\title{
Museum Learning 2.0: How (can) Web 2.0 technologies be used for enhancing the museum learning experience?
}

\author{
Koula Charitonos \\ Canan Blake \\ Eileen Scanlon, Ann Jones \\ Institute of Educational Technology \\ The Open University \\ Walton Hall, Milton Keynes MK7 6AA \\ k.charitonos@open.ac.uk \\ c.blake@open.ac.uk \\ e.scanlon@open.ac.uk \\ a.c.jones@open.ac.uk
}

\section{INTRODUCTION}

Social media has emerged as a prominent element in the current digital landscape and its widespread use reflects how Web 2.0 technologies have become embedded in our lives. Use of social media technologies for learning signals a departure from the use of purely educational or institutional technologies, where educators or the institutions control the technology and the content and impose the rules. This development brings unique and fundamental opportunities, alongside challenges, for rethinking learning in museums. In a museum context, social media tools may make it possible for people to situate objects within contextual information, enable users to make links with other objects or topics and initiate discussions among them. These processes highlight the social aspect of museum experience, advocated by Falk and Dierking $(1992 ; 2000)$, and it is thus hypothesised that use of social media will lead to - and enhance a shared understanding around objects, which will facilitate the meaning-making process and thus, learning. The study presented in this paper (part of a $\mathrm{PhD}$ research project) is concerned with the potential of Web 2.0 technologies for enhancing young people's museum learning experience and facilitating their meaning-making process. Museum of London

(http://www.museumoflondon.org.uk/English/) is selected as the site of the study. The participants were a Year 9 History class (13-14 years old) in a secondary school located in Milton Keynes. The research project was designed around the theme 'Get Up, Stand Up for your Rights' and is related to the KS3 Scheme of Work 'Equality and Beliefs'. It included a number of classroom-based sessions and $a$ visit to the museum in March 2011. During the museum visit, the students in groups explored the museum's collections by using mobile phones to take pictures and broadcast short messages on Twitter (http://twitter.com), in relation to a learning inquiry assigned to them. The participants also used museum's e-learning studio and school's ICT suite to create online collages on Vuvox. (www.vuvox.com). This presentation aims to outline this research in progress and to examine whether and how can the use of social media facilitate interactions among young people, that can be potentially enhance their museum experience. The paper will present data collected by using Twitter during the school's visit to the MoL. It draws on Falk and Dierking's (2000) Contextual Model of Learning and considers evidence of meaning making from students' tweets and activity on-site. It discusses initial findings in order to develop an agenda for future research to explore whether and how can social interactions online facilitate the meaning-making process and lead to a shared understanding around museum artifacts.

\section{REFERENCES}

Falk, H., J. and Dierking, D., L. (1992). The Museum Experience. Washington: Whalesback Books

Falk, H., J. and Dierking, D., L. (2000) Learning from Museums. Visitors Experiences and the Making of Meaning. AltaMira Press: Walnut Creek 